\title{
Dynamical Response of the South Asian Monsoon Trough to Latent Heating from Stratiform and Convective Precipitation
}

\author{
AyANTIKA Dey ChOUdhury AND R. KRISHNAN \\ Centre for Climate Change Research, Indian Institute of Tropical Meteorology, Pashan, India
}

(Manuscript received 15 October 2010, in final form 31 January 2011)

\begin{abstract}
Simulation experiments using a simplified atmospheric GCM and supplementary diagnostic analyses of observations are performed to understand how the South Asian monsoon trough (MT) responds dynamically to latent heating from mesoscale convective systems (MCSs). Observations reveal that the MT during active monsoons is characterized by a deep cyclonic vorticity extending from the surface to $350 \mathrm{hPa}$ and organized MCSs covering over $3500-4000 \mathrm{~km}$ along the Indo-Gangetic plains. The MCSs during active monsoons are composed of a relatively higher abundance of stratiform-type precipitation (mostly nimbostratus) as compared to the convective type. The results suggest that a stratiform-type heating profile is very effective in promoting upward development of continental-scale cyclonic circulation well above the midtroposphere over the MT region. The vertical development involves a dynamical uplift of the layer of cyclonic circulation and is induced by midlevel $(600-500 \mathrm{hPa})$ convergence and vorticity stretching above $500 \mathrm{hPa}$. By varying the population of stratiform and convective rain types in the simulation, the horizontal scale of midlevel vorticity response is shown to increase significantly with stratiform population; in contrast, the midlevel response is more localized when the MCS is dominated by deep convective clouds. For large stratiform populations, the midlevel response is found to extend far westward up to the northern flanks of the African ITCZ, indicative of Rossby wave dispersion of PV anomalies that are generated near the level of maximum heating gradient. From the present findings, one can conclude that the vertical deepening of MT during active monsoons is not merely a localized phenomenon; instead it represents a large-scale dynamical response to organized MCSs that exert pivotal influence on the upward development of cyclonic circulation well above the midtroposphere.
\end{abstract}

\section{Introduction}

The monsoon trough (MT) is a salient feature of the South Asian summer monsoon that has been well documented in the literature (e.g., Anjaneyalu 1969; Rao 1976; Koteswaram and Rao 1963; Krishnamurti and Surgi 1987; Sikka and Narasimha 1995; Wang 2004). The MT manifests as a low pressure zone extending from northwestern India and adjoining Pakistan towards the Gangetic plains, the Bay of Bengal, and farther eastward, as evidenced in a typical weather chart (Fig. 1). The kinetic energy of the mean MT is maintained by the pressure gradient of the large-scale monsoon circulation (Keshavamurty and Awade 1970). The dynamic and thermodynamic conditions are different over the eastern and western flanks of the MT (Sikka and Narasimha

Corresponding author address: R. Krishnan, Centre for Climate Change Research, Indian Institute of Tropical Meteorology, Pashan, Pune 411008, India.

E-mail: krish@tropmet.res.in
1995). The western part is characterized by a heat low located over a dry region, where convection is generally shallow and updrafts are restricted near to the surface. The eastern part, often called the dynamic trough, is a region of moist instability and deep convection. Rainfall activity over the north-central Indian plains is closely related to the position and intensity of the MT (Rao 1976; Das 1986). During inactive or break monsoons, the cessation of rains over central India is accompanied by high pressure anomalies and the MT shifts to the Himalayan foothills (e.g. Ramamurthy 1969; Krishnamurti and Ardanuy 1980; Krishnan et al. 2000, 2009). During active monsoons, the MT has an east-west orientation and rainfall activity is associated with embedded synoptic systems such as lows, depressions, and midtropospheric cyclones (e.g., Miller and Keshavamurthy 1968; Alexander et al. 1978; Krishnamurti and Surgi 1987).

The MT has received extensive attention in the literature as a feature in the boundary layer and lower troposphere (e.g., Rao 1976; Krishnamurti and Bhalme 1976; Das and Bedi 1981; Sikka and Gadgil 1980; Narasimha 

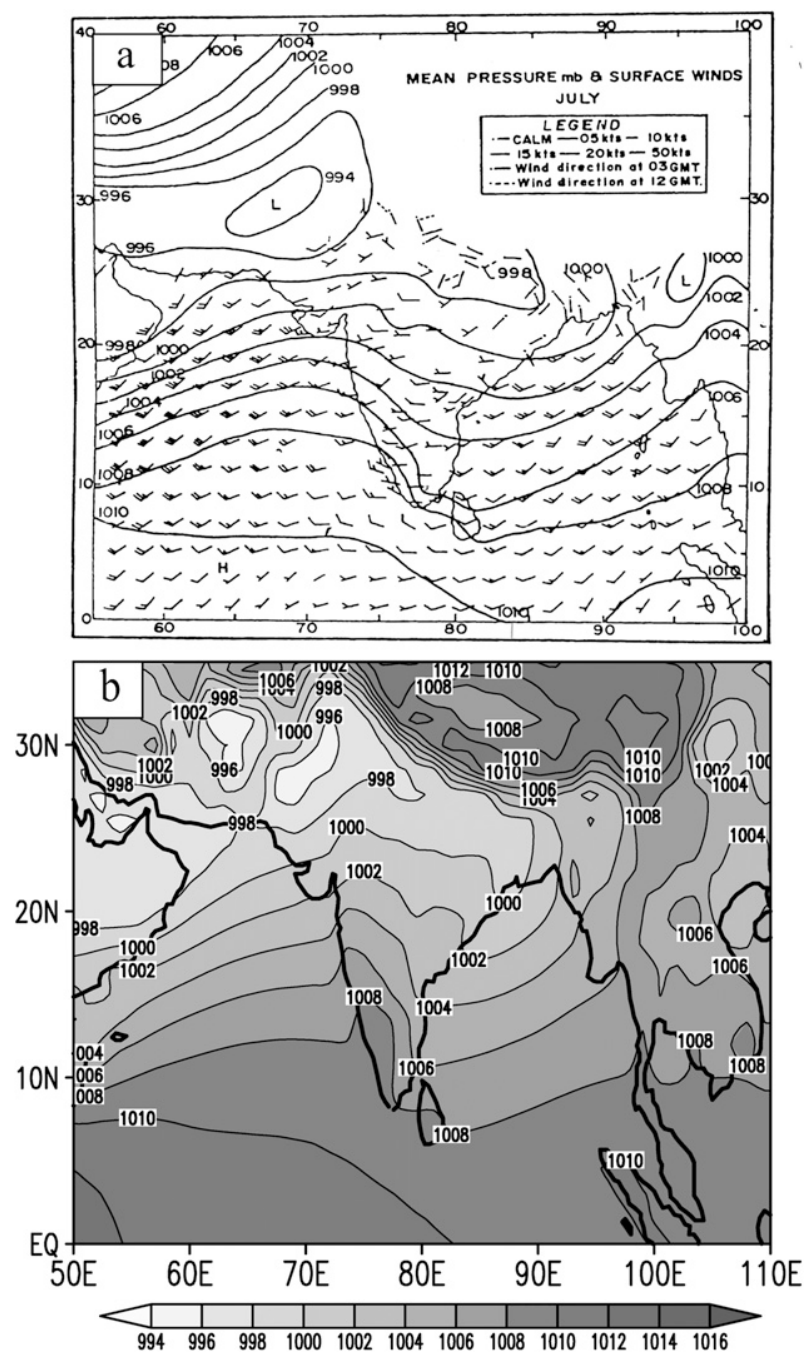

FIG. 1. (a) Mean sea level pressure (contours, hPa) and surface wind (barbs, kt) distribution during the month of July (taken from Sikka and Narasimha 1995). (b) Climatological July mean sea level pressure $(\mathrm{hPa})$ obtained from the ERA-Interim dataset. Climatology is based on the period 1989-2008.

et al. 1997) and also as a circulation feature characterized by intermittent intensifications over central India up to $500 \mathrm{hPa}$ during active monsoon periods (e.g., Alexander et al. 1978). However, a key aspect of the MT that has been hitherto overlooked by earlier studies is its large-scale character that is conducive for upward development of cyclonic circulation well above the midtroposphere. In fact, this feature can be noticed during active monsoons as evidenced from the reanalysis circulation data (see Fig. 4). The specific question addressed here is the role of latent heating distribution on the vertical development of the continental-scale circulation response above the midtropospheric levels over the MT region. Simple models based on the first baroclinic vertical mode of heating mostly explain the large-scale monsoon response in the lower and upper tropospheric levels (e.g., Gill 1980), while the midtropospheric circulation response is weak in this case due to the low values of midlevel convergence. On the other hand, nonidealized models that calculate latent heating interactively using parameterized moist convection have major challenges in producing realistic heating fields. Krishnamurti et al. (2010) examined the performance of some of the current cumulus parameterization schemes in describing the amplitude and three-dimensional distributions of heating over the Indian monsoon region as observed by the Tropical Rainfall Measuring Mission (TRMM) satellite during July 2007. They noted large errors in the vertical structure of model-derived latent heating and the placement of the vertical level of maximum heating. Such inaccuracies in the heating distribution produce erroneous convergence/divergence centers, in turn leading to deficiencies in the simulated large-scale response.

Mesoscale convective systems (MCSs) over the tropics provide an important link between atmospheric convection and large-scale circulation (Houze 2004). Radar observations indicate that convection-generated MCSs over the tropics are composed of evolving patterns of convective and stratiform precipitation in which vigorous convection occurs in the young portions of the MCS, whereas weaker updrafts due to stratiform precipitation occur in older portions extending over larger areas (e.g., Houze 1982, 1997, 2004; Mapes 1993; Mapes and Houze 1995). Furthermore, synoptic environments over the South Asian monsoon region (e.g., lows and depressions) are known to reveal a preponderance of stratiform precipitation wherein updrafts are forced by large-scale vertical ascent of the monsoon disturbances (e.g., Houze and Churchill 1987; Stano et al. 2002; Houze et al. 2007; Krishnan et al. 2011; Romatschke and Houze 2011). The growth mechanisms of precipitation particles and structure of heating profiles are different for the stratiform and convective cloud systems (e.g., Houghton 1968; Houze 2004; Mapes 1993; Schumacher et al. 2004; Kodama et al. 2009). The characteristic vertical profile of latent heating for convective precipitation has a single peak in the midtroposphere, while the stratiform precipitation type is characterized by cooling in the lower troposphere and an elevated heating peak in the upper levels at a height of approximately $8 \mathrm{~km}$.

Theoretical and GCM-based investigations suggest that the vertical gradient of heating from stratiform-type clouds is far more effective in elevating the circulation centers and strengthening the upper-tropospheric response of the tropical Walker and Hadley circulations as compared to deep convective clouds (e.g., Geisler and Stevens 1982; Hartmann et al. 1984; Mapes 1993; 

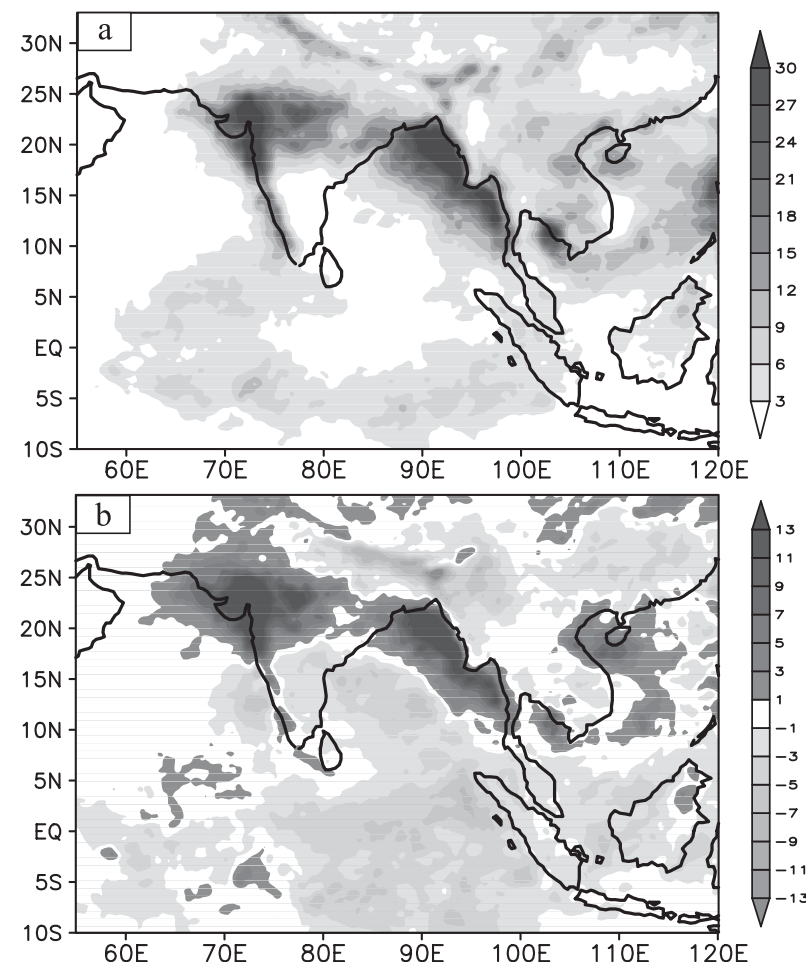

FIG. 2. Composites based on active monsoon days: (a) total rainfall $\left(\mathrm{mm} \mathrm{day}^{-1}\right)$ and (b) rainfall anomaly $\left(\mathrm{mm} \mathrm{day}^{-1}\right)$ based on 3B42 daily rainfall data. The active monsoon days considered for the present study are given in Table 1 .

Schumacher et al. 2004). Studies have also reported the importance of stratiform heating on the evolution of tropical low-frequency intraseasonal oscillations (e.g., Jiang et al. 2009; Chattopadhyay et al. 2009). In the context of the large-scale dynamics of the MT, one of the unresolved questions is the role of convective and stratiform components of the MCS on the upward development of cyclonic circulation well above the midtroposphere. In this paper, we have performed simplified GCM simulation experiments supplemented by diagnostic analysis of observations in order to address the above issue. This is an important problem given the fact that the rainfall enhancement during active monsoons can last from a few days to beyond a week (Rajeevan et al. 2010) and the scale of the rainfall anomaly can extend spatially over approximately $4000 \mathrm{~km}$ from west-central India up to the South China Sea (Fig. 2). Furthermore, this study has implications for improving our ability to simulate the MT through development of realistic cumulus parameterization schemes for the monsoon region.

\section{Datasets and model details}

Datasets from multiple sources are utilized in this study. These include daily rainfall over global tropics derived from satellite measurements, the TRMM and other rainfall estimates (e.g., 3B42) (Huffman et al. 1995, 1997) and the TRMM Precipitation Radar (PR) 2 A25 data of rain rate and rain type information (Iguchi et al. 2000). The $3 \mathrm{~B} 42$ daily rainfall dataset, which is available for the period 1997-present, is a level-3 product obtained by daily accumulation of rainfall from the 3-hourly product. It provides time-resolved TRMM adjusted merged infrared precipitation estimates with complete regional coverage (Huffman et al. 1995, 1997) at a horizontal resolution of $0.25^{\circ} \times 0.25^{\circ}$. The TRMM 2 A25 data consist of a level-2 rainfall rate and profile product at $4 \mathrm{~km} \times 4 \mathrm{~km}$ horizontal resolution. The convective/ stratiform rain classification is based on the vertical profile and horizontal distribution of radar echo and existence of a bright band as described originally by the 2A23 algorithm (Awaka et al. 1997). This is used as input in the 2A25 algorithm for rain rate estimation. Stratiform areas identified by the TRMM algorithm have less vigorous convection and are dominated by weak updrafts with large spatial extent. Additionally the TRMM PR 3A25 monthly gridded rainfall is used in the study. This a level-3 product that computes monthly averages of rain parameters in a $0.5^{\circ} \times 0.5^{\circ}$ grid box using level-2 PR products (Meneghini et al. 2001). For all TRMM products, the climatology is relative to the period 1998-2007. (All TRMM products are obtained via ftp from disc2.nascom.nasa.gov). Atmospheric winds from the interim European Centre for Medium-Range Weather Forecasts (ECMWF) Re-Analysis (ERA-Interim; Simmons et al. 2006) obtained from the ECMWF data server for the period 1989-2008 have been used to diagnose the circulation anomalies during active monsoons and to validate the model simulations. The wind data are available at $1.5^{\circ} \times 1.5^{\circ}$ horizontal resolution on 37 pressure levels. Additionally, we have analyzed the ERA-Interim potential vorticity (PV) field on the 330-K isentropic surface to interpret the results. The baseline climatology for the ERA-Interim fields is 1989-2008.

For the numerical simulations, we have used a simplified dry global atmospheric GCM. The GCM has a horizontal resolution at R40 (i.e., rhomboidal truncation at zonal wavenumber 40 ) with 25 vertical sigma levels $\left(\sigma=p / p_{s}\right.$, where $p_{s}$ is surface pressure). The model does not include representation of orography. The model formulation is based on Bourke (1974) and an earlier version of this model with five vertical levels has been extensively used for studying problems on monsoon and tropical dynamics (e.g., Keshavamurty et al. 1986; Kasture et al. 1991; Krishnakumar et al. 1993; Krishnan and Kasture 1995, 1996). In the present version (R40L25), we have increased the number of vertical $\sigma$ levels to 25, which is important for resolving the 
TABLE 1. List of active monsoon days based on Rajeevan et al. (2010).

\begin{tabular}{ll}
\hline \hline Year & \multicolumn{1}{c}{ Active monsoon spells } \\
\hline 1998 & 3-6 July \\
2000 & 12-15 July, 17-20 July \\
2001 & 9-12 July \\
2003 & 26-28 July \\
2004 & 30 July-1 August \\
2005 & 1-4 July, 27 July-1 August \\
2006 & 3-6 July, 28 July-2 August, 5-7 August, 13-22 August \\
2007 & 1-4 July, 6-9 July, 6-9 August \\
\hline
\end{tabular}

vertical variation of response to latent heating. The $25 \sigma$ levels correspond to $\sigma=0.98,0.94,0.90, \ldots \ldots, 0.06$, 0.02 . The simplicity of the model is a major advantage in that the results are amenable to straightforward interpretation of the dynamical response. Further details of the R40L25 model are described in Sundaram et al. (2010) and the design of the experiments is discussed in section 4 .

\section{Observed anomalies of rainfall and large-scale circulation during active monsoons}

\section{a. Rainfall distribution}

Figure 2 shows composite maps of total rainfall and rainfall anomaly, based on the daily TRMM 3B42 dataset, constructed by averaging the fields over all the active monsoon days (Table 1). The daily rainfall anomalies are relative to the daily climatological mean for the period 1998-2007. We have used the active monsoon dates as defined by Rajeevan et al. (2010) based on the daily gridded observed rainfall dataset of the India Meteorological Department (IMD). Rajeevan et al. (2010) identified active monsoons as episodes when the normalized rainfall anomaly over a core monsoon zone in north-central India exceeded one standard deviation for at least three consecutive days. The spatial domain of the core monsoon zone (see Rajeevan et al. 2010) represents a fairly wide region that is part of the boreal summer monsoon ITCZ over the Indian subcontinent. Therefore, active monsoon conditions basically correspond to periods of large-scale organization of convection along the MT region. This is clearly evident from the horizontal scale of the east-west band of enhanced rainfall anomaly that extends southeastward from western India into the Bay of Bengal, Myanmar, and up to the South China Sea in Fig. 2b. While some areas over the MT presumably may not experience active rains at the same time, the important point is that a very large area experiences surplus rainfall because of the extended time and large spatial scales. It may be noticed that rainfall

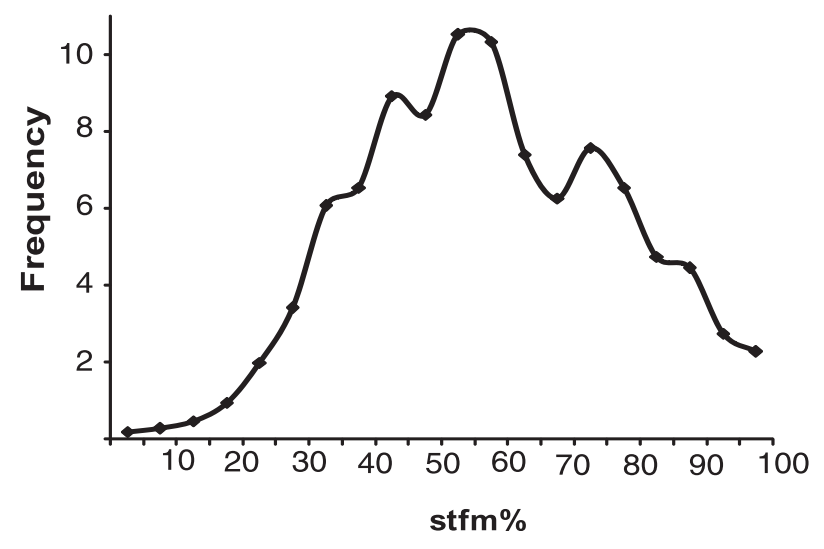

FIG. 3. Normalized frequency distribution of stratiform rain fraction over the MT region $\left(16^{\circ}-25^{\circ} \mathrm{N}, 65^{\circ}-98^{\circ} \mathrm{E}\right)$ based on the active monsoon days in Table 1 . The data are based on the TRMM PR 2A25 rainfall product.

over peninsular India and the equatorial Indian Ocean is below normal (Fig. 2b).

Figure 3 shows the frequency distribution of stratiform rain fraction obtained from TRMM PR passes over the MT zone $\left(16^{\circ}-25^{\circ} \mathrm{N}, 65^{\circ}-98^{\circ} \mathrm{E}\right)$ during active monsoon conditions. The frequency distribution shows maximum probability corresponding to the $50 \%$ stratiform rain fraction. It is also important to note that the frequency of occurrence of stratiform rain fractions in the $50 \%-80 \%$ range is quite high. The large population of stratiform clouds during active monsoons is often associated with low pressure systems over the region (e.g., Stano et al. 2002; Houze et al. 2007; Krishnan et al. 2011). An examination of rain and reflectivity from TRMM PR-2A25 passes during a typical active monsoon period (15-17 August 2006) revealed organized precipitating systems extending over several hundred kilometers (not shown). The vertical cross sections of radar echoes and rain rate showed fairly uniform horizontal distribution with embedded vertical spikes, as well as the presence of a bright band near $5 \mathrm{~km}$ indicating stratiform processes covering several hundred kilometers with embedded convective cells (not shown). For the same dates (15-17 August 2006), we have also verified the heating profiles from the convective-stratiform heating (CSH) dataset of Tao et al. (2001) over the MT region. It is noted that the maximum latent heating occurred around $8 \mathrm{~km}$ (not shown). These points suggest that active monsoons over the MT region may involve significant contributions from nimbostratus clouds (see Stano et al. 2002).

\section{b. Circulation anomalies}

Using the ERA-Interim data, we shall now examine the circulation anomalies during active monsoons. The anomaly composites of circulation fields have been prepared 


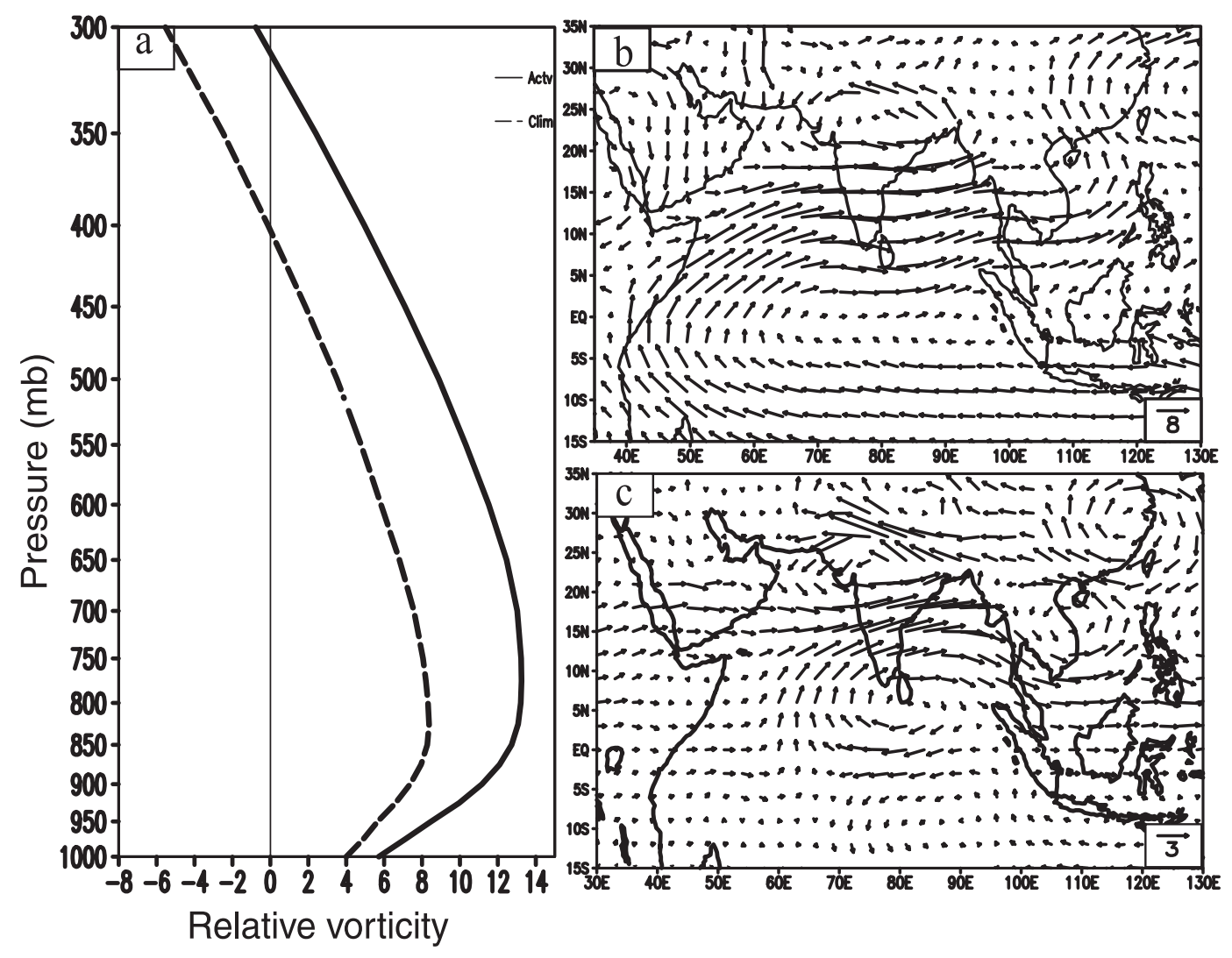

FIG. 4. (a) Relative vorticity $\left(\times 10^{-6} \mathrm{~s}^{-1}\right)$ profiles averaged over MT region $\left(16^{\circ}-28^{\circ} \mathrm{N}, 65^{\circ}-100^{\circ} \mathrm{E}\right)$. The solid line is for $\zeta_{A}$ and the dashed line is $\zeta_{C}$. (b),(c) Composite maps of vertically averaged (surface-350 hPa) circulation during active monsoons, showing (b) total wind field $\left(\mathrm{m} \mathrm{s}^{-1}\right)$ and (c) wind anomaly $\left(\mathrm{m} \mathrm{s}^{-1}\right)$. The data are based on the ERAInterim dataset and the climatology is based on the period 1989-2008.

by averaging the daily wind anomalies over all the active monsoon days given in Table 1 . The vertical profile of relative vorticity $\zeta$ averaged over the MT zone $\left(16^{\circ}\right.$ $28^{\circ} \mathrm{N}, 65^{\circ}-100^{\circ} \mathrm{E}$ ) is shown in Fig. 4a. The solid curve $\left(\zeta_{A}\right)$ is the relative vorticity profile composited from all the active monsoon days in Table 1 . The dashed curve $\left(\zeta_{C}\right)$ is the relative vorticity profile corresponding to the climatological mean winds for the period 1989-2008. It can be noticed that the cyclonic vorticity in $\zeta_{A}$ is significantly enhanced as compared to $\zeta_{C}$, and the intensified cyclonic vorticity in $\zeta_{A}$ can be seen extending up to $350 \mathrm{hPa}$. In the lower levels, from the surface to $800 \mathrm{mb}$, the magnitude of $\zeta_{A}$ is about 1.5 times greater than that of $\zeta_{C}$. The enhancement of cyclonic vorticity of $\zeta_{A}$ is even more striking in the midtropospheric levels. In addition, it is interesting to note that the cyclonic vorticity of $\zeta_{A}$ has a deeper vertical extent $(\sim 350 \mathrm{hPa})$ relative to that of $\zeta_{C}(\sim 450 \mathrm{hPa})$.

Figure $4 \mathrm{~b}$ shows the composite map of vertically averaged winds from the surface to $350 \mathrm{hPa}$ based on the active monsoon days in Table 1 . One can notice that the large-scale cross-equatorial flow of the southwest monsoon is accompanied by a cyclonic circulation over northcentral India. It can be noticed that the eastern side of the cyclonic vortex extends into Indo-China and the South China Sea in the form of a trough. The anomalous intensification of the MT is clearly evidenced in Fig. 4c, which shows the active monsoon composite plot of vertically averaged wind anomalies. One can clearly see that the cyclonic anomaly of the MT extends zonally from about $60^{\circ} \mathrm{E}$ to about $120^{\circ} \mathrm{E}$. Anomalous westerlies over $10^{\circ}-20^{\circ} \mathrm{N}$ can be seen from the African region into South Asia and farther eastward. Another interesting feature in Fig. 4c is the intensified southwesterly flow over Arabian Sea along the northern flank of the anomalous anticyclone over equatorial Indian Ocean and southern India.

Wind anomaly composites at different pressure levels, which are shown in Figs. 5a-f, provide useful information about the vertical structure of the circulation anomalies association with the upward development of the layer exhibiting cyclonic flow over the MT. The statistical significance of the zonal wind anomaly composite is shown by shading in Fig. 5. The statistical significance 

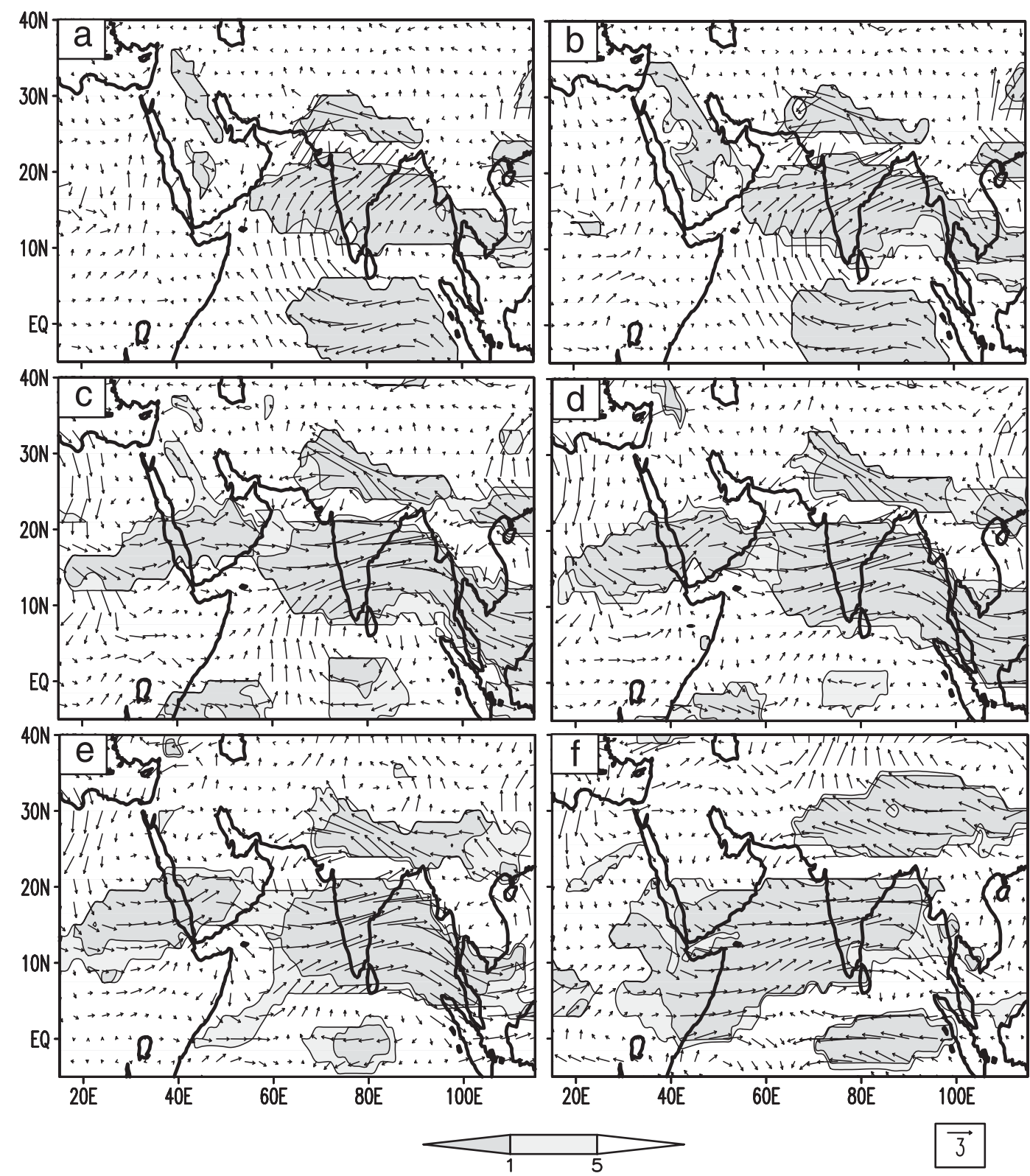

FIG. 5. Wind anomaly (arrows, $\mathrm{m} \mathrm{s}^{-1}$ ) composites and statistical levels of significance (shading, \%) of zonal wind anomaly based on active monsoon days at (a) 925, (b) 850, (c) 700, (d) 600, (e) 500, and (f) $350 \mathrm{hPa}$. The data are based on the ERA-Interim reanalysis.

has been evaluated using the Student's $t$ test for unequal variances (Press et al. 1992,611-612). This approach was used by Krishnan et al. (2000) to test the statistical significance of convection anomalies during monsoon breaks. The shaded area in Fig. 5 shows regions where the zonal wind anomaly is significant at $1 \%$ and $5 \%$ levels. The anomalies of wind vectors are superposed on the significance levels maps. It can be noticed that at the nearsurface levels (e.g., $925 \mathrm{hPa}$ ), the cyclonic anomaly is located mostly over the Indian landmass. As we proceed upward, the horizontal scale of the cyclonic anomaly increases. In the layer between 700 and $350 \mathrm{hPa}$, the cyclonic anomaly can be seen stretching over several thousand kilometers from nearly $60^{\circ} \mathrm{E}$ up to $120^{\circ} \mathrm{E}$. It is important to note that this continental-scale cyclonic anomaly, associated with the MT intensification, has maximum amplitude in the midtropospheric levels. It is also interesting to note that the anomalous monsoon cross-equatorial flow is prominent in the lower levels, while the midtropospheric circulation is dominated by 
TABLE 2. Design of GCM experiments by varying the stratiform and convective fractions of the monsoon rainfall anomaly over the MT region.

\begin{tabular}{cccccc}
\hline \hline & $\begin{array}{c}\text { Fractions of rainfall } \\
\text { anomaly during active } \\
\text { monsoon period (\%) }\end{array}$ & & \multicolumn{2}{c}{$\begin{array}{c}\text { Active period rainfall } \\
\text { anomaly (\%) }\end{array}$} \\
\cline { 2 - 3 } \cline { 5 - 6 } Experiment & $\begin{array}{c}\text { Stratiform } \\
\text { fraction (SF) }\end{array}$ & $\begin{array}{c}\text { Convective } \\
\text { fraction (CF) }\end{array}$ & $\begin{array}{c}\text { Stratiform } \\
\text { anomaly }\end{array}$ & $\begin{array}{c}\text { Convective } \\
\text { anomaly }\end{array}$ \\
\cline { 1 - 3 } EXP1 & 0 & 100 & & 0 & 100 \\
EXP2 & 30 & 70 & & 30 & 70 \\
EXP3 & 50 & 50 & & 50 & 50 \\
EXP4 & 70 & 30 & & 70 & 30 \\
\hline
\end{tabular}

large-scale westerly anomalies from the African region passing over the Arabian Sea into the Indian subcontinent and extending farther toward Southeast Asia and the South China Sea. It can be seen that the continentalscale midtropospheric westerly wind anomalies are statistically significant.

\section{GCM simulated response to stratiform/ convective-type latent heating}

In this section we shall describe the GCM experiments that were conducted to understand the MT response to latent heating associated with the MCS. The set of GCM experiments that were conducted is described in Table 2. In each of these experiments, the R40L25 GCM is forced with specified latent heating and integrated to obtain a steady-state response. The different experiments in Table 2 basically differ in terms of the prescribed latent heating. Since latent heating is the dominant component of the total diabatic heating (Schumacher et al. 2004), the main focus here is on the response of the MT to latent heating associated with the monsoon MCS. The initial condition in all the model experiments corresponds to an atmosphere at rest. The initial temperatures at the different vertical levels of the model correspond to the global mean values at the respective level (Bourke 1974). In the model formulation, the temperature field at a given sigma level is expressed as a sum of the global mean and the deviation from the global mean. The model uses Rayleigh friction and Newtonian cooling terms, both having an $e$-folding decay time scale of 5 days (see Krishnan and Kasture 1996; Sundaram et al. 2010). In all the experiments, the model is integrated for 100 days by keeping the heating and linear damping terms fixed through the course of integration. It is noted that the model attains a near-equilibrium state well before 100 days of integration. The simulation at the end of day 100 is taken as the steady-state response. This approach of obtaining the steady-state response is similar to other studies (e.g., Hoskins and Rodwell 1995;
Schumacher et al. 2004). The specification of latent heating in the different model experiments is described in the next section.

\section{a. Latent heating in the control experiment}

In the control experiment (CTRL), the model is forced by the three-dimensional June-September (JJAS) climatological latent heating constructed using surface rain estimates from the TRMM PR 3A25 monthly rainfall dataset and assumed vertical profiles of stratiform and convective precipitation based on Schumacher et al. (2004). It has been noted that the spatial distribution of the 3A25 surface rainfall climatology compares well with that of the observed rain gauge data from the IMD, although the magnitude is underestimated in 3A25 over central India and Western Ghats as compared to the IMD dataset (not shown). Other studies have also reported an underestimation of precipitation especially over land areas in the PR 3A25 (Iguchi et al. 2009; Romatschke and Houze 2011). However, since the PR 3A25 provides more accurate estimates of surface rain and stratiform/ convective rain partitioning, with complete coverage over global tropics as compared to other satellite products (e.g., the 3A12 microwave product), we have used the PR 3A25 dataset to derive the climatological JJAS baseline heating. The three-dimensional latent heating at every grid-box is computed using the JJAS mean surface rain rate, stratiform/convective rain fractions and a linear combination of assumed vertical profiles of stratiform and convective precipitation based on Schumacher et al. (2004). The assumed latent heating profile for the deep convective rain is positive throughout the troposphere; while the stratiform profile is characterized by heating above the $0^{\circ} \mathrm{C}$ level and cooling below.

The vertically averaged climatological JJAS latent heating over the Asian monsoon region is shown in Fig. 6a. The latent heating field has maxima over the head of the Bay of Bengal, off the Myanmar region, and over the western coast of India; the heating field extends southeastward from the Indian landmass into the Bay of Bengal, Southeast Asia, the South China Sea, and the tropical western Pacific. Clearly the latent heating over the region during the boreal summer monsoon is located mostly to the north of the equator around the $10^{\circ}-20^{\circ} \mathrm{N}$ latitude belt. Additionally, one can notice significant heating over the east-central equatorial Indian Ocean, which is associated with the secondary oceanic convergence zone (e.g., Yasunari 1979; Sikka and Gadgil 1980; Krishnan et al. 2003, 2006). Although the model does not include orography explicitly, it is important to note that the effect of orography has in effect been accounted for in the imposed geographical distribution of heating based on the observed rainfall. In fact, this aspect can be 

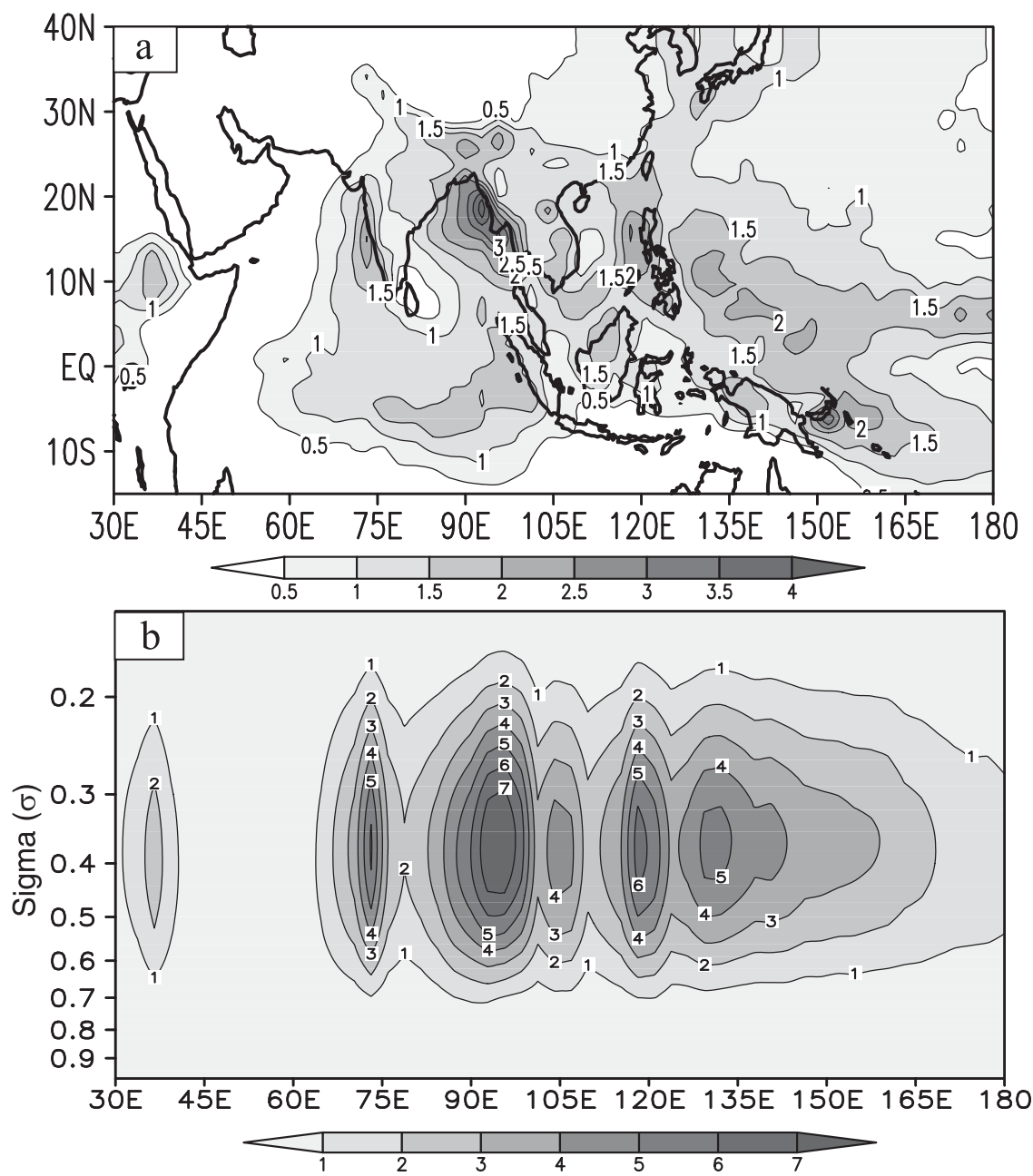

FIG. 6. Climatological JJAS latent heating $\left(\mathrm{K} \mathrm{day}^{-1}\right)$ derived based on the algorithm of Schumacher et al. (2004) by utilizing the PR 3A25 monthly rainfall products: (a) vertically averaged heating and (b) height-longitude section averaged over $10^{\circ}-20^{\circ} \mathrm{N}$.

readily recognized from the strong latent heating over the Western Ghats and the orographic regions of Myanmar and the eastern Himalayas in Fig. 6a.

The height-latitude section of climatological latent heating (Fig. 6b) averaged over $10^{\circ}-20^{\circ} \mathrm{N}$ shows pronounced heating above the middle troposphere across the $75^{\circ}-105^{\circ} \mathrm{E}$ longitudes of the South and Southeast Asian monsoon regions. This is consistent with the results of Kodama et al. (2009), who noted that heating over Bay of Bengal has a maximum value exceeding $5 \mathrm{~K} \mathrm{day}^{-1}$ at an altitude of 6-7 km during the summer monsoon. With regard to the heating around $90^{\circ} \mathrm{E}$, studies have pointed out that the warm bay supports larger MCS with higher stratiform rain fractions that contribute to strong upper-level heating (e.g., Cetrone and Houze 2009; Romatschke and Houze 2011). We have compared the climatological latent heating constructed in Fig. 6 with the CSH heating product of Tao et al. (2001). It is noted that the spatial distribution of vertically averaged heating and the placement of the vertical level of maximum heating are comparable in both the datasets. However, the magnitude of maximum heating used in our study overestimates that of the Tao et al. (2001) heating by $1-2 \mathrm{~K} \mathrm{day}^{-1}$, particularly over the orographic precipitation regions of Western Ghats, the Myanmar coast, etc. (not shown).

\section{b. Latent heating in the sensitivity experiments}

Following the control experiment, we have performed four sensitivity experiments (EXP1, EXP2, EXP3, and EXP4) to examine the anomalous response of MT to varying populations of stratiform and convective clouds associated with the MCS during active monsoons. The latent heating for the four sensitivity experiments is 

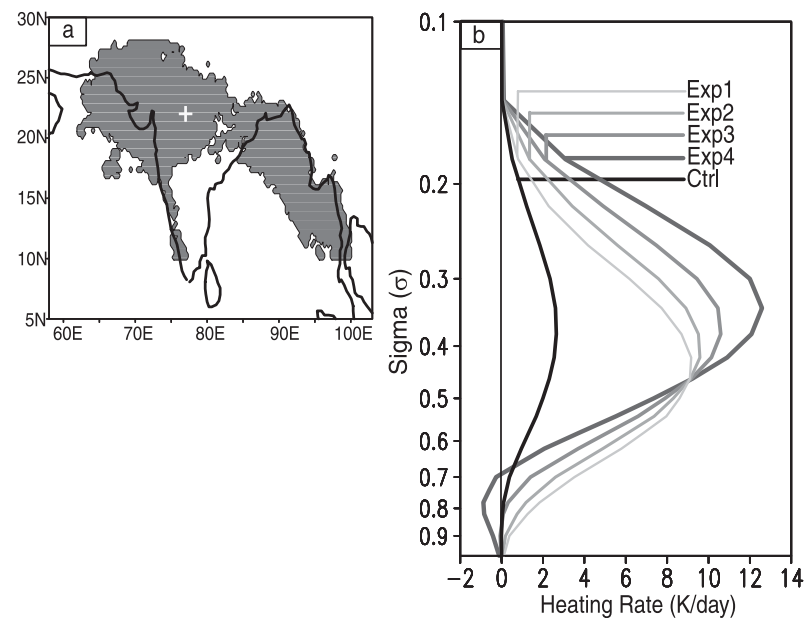

FIG. 7. (a) Region used for constructing active monsoon heating anomaly shown by shading. (b) Heating profiles $\left(\mathrm{K} \mathrm{day}^{-1}\right)$ for the four experiments shown at a representative grid point $\left(22^{\circ} \mathrm{N}, 77^{\circ} \mathrm{E}\right)$ in the MT. The representative grid point is indicated by a cross in (a).

constructed as follows. The rainfall anomaly pattern during the active monsoon phase (Fig. 2b) based on the TRMM 3B42 is first extracted over an extended region shown by shading in Fig. 7a. The shaded region basically corresponds to the zone of monsoon MCS oriented along the axis of the MT. The 3B42 rainfall anomaly over this region is superposed on the PR 3A25 JJAS climatological mean rainfall to get the total rain. Since the model sensitivity experiments require the specification of time-resolved latent heating with complete regional coverage, we have used the TRMM 3B42 rainfall data to calculate the active period rain anomaly.

The four sensitivity experiments are designed such that they represent four different cases of stratiform and convective rain fractions (SF and $\mathrm{CF}$, respectively) associated with the enhanced rainfall anomaly over the monsoon MCS zone. The (SF, CF) in the four experiments EXP1, EXP2, EXP3, and EXP4 are chosen to be $(0,100),(30,70),(50,50)$, and $(70,30)$, respectively (see Table 2). Note that the percentage of SF progressively increases from EXP1 to EXP4. Although we allow for the spatial variation of total rainfall over the monsoon MCS zone, it is assumed that the SF and $\mathrm{CF}$ of the rain anomaly for any particular experiment have fixed values at all the grid points over the MCS zone. This simplification has been made to facilitate straightforward interpretation of the model simulations. The threedimensional heating is calculated using the total rainfall, stratiform/convective rain fractions, and the assumed heating profiles for the four different cases following the algorithm of Schumacher et al. (2004). Basically, the total heating for a given experiment is a superposition of the climatological baseline heating whose vertical structure varies at each grid box according to the local climatological stratiform/convective partitioning and an anomaly heating profile whose vertical structure is the same everywhere over the MCS zone. Since the stratiform/ convective partitioning of the rain anomaly varies among the four experiments, the vertical structure of the heating anomaly over the MCS zone differs from one experiment to another. Figure $7 \mathrm{~b}$ shows the vertical profiles of latent heating for the four experiments over a typical location in the Indo-Gangetic plains. It can be noticed that as the percentage of SF is increased, the level of maximum heating is progressively elevated. Also, as the heating increases in upper levels, its magnitude decreases in the lower levels.

\section{c. GCM simulated mean response in CTRL experiment}

The CTRL simulation provides the baseline for comparing the sensitivity experiments. Here, we focus on the low-level and midlevel circulation responses that are relevant for the present study. Figure 8a shows the vertically averaged winds and streamfunction response for the low levels $(\sigma=0.98-0.66)$. The CTRL simulation shows the major semipermanent features of the boreal summer monsoon circulation, which include the monsoon cross-equatorial flow and southwesterly winds over the Arabian Sea, the Indian region and Bay of Bengal, the cyclonic circulation over the MT, the easterly trades over the Pacific, and the subtropical highs over the $\mathrm{Pa}$ cific and Indian Oceans. These large-scale circulation features are broadly consistent with observations and simulations forced with observed diabatic heating (e.g., Zhang and Krishnamurti 1996; Rodwell and Hoskins 1996; Sundaram et al. 2010). The circulation response in the CTRL simulation averaged for the midlevels $(\sigma=$ 0.62-0.30) is shown in Fig. 8b. The midlevel response shows a zonally extended cyclonic circulation stretching from the horn of Africa, across the Arabian Sea, India, the Bay of Bengal, Southeast Asia, and the South China Sea up to the Philippines region. The above midlevel circulation features are found to be broadly consistent with the ERA-Interim reanalysis data (not shown). Since the model forcing does not include longwave radiative cooling, the subtropical anticyclones associated with subsidence are somewhat weak in the simulation. Nevertheless, the broad features of the global tropical circulation are reasonably captured in the CTRL simulation.

\section{d. GCM response to varying stratiform/convective rain fractions of monsoon MCS}

Here, we examine the anomalous response in the four sensitivity experiments by subtracting the response from the CTRL run. The low-level circulation anomalies for 

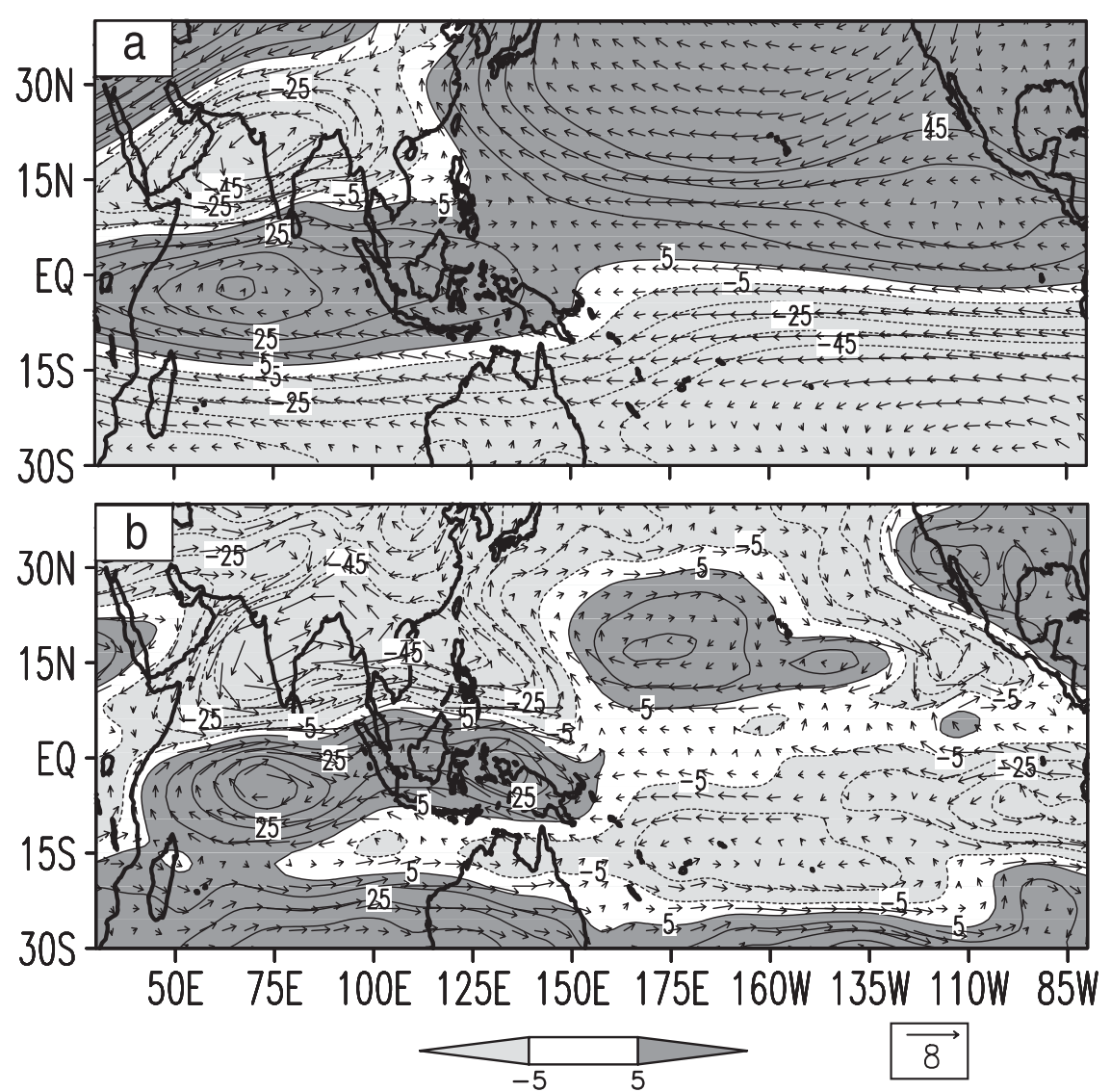

FIG. 8. Simulation of streamfunction $\psi$ (shading, $\times 10^{-5} \mathrm{~m}^{2} \mathrm{~s}^{-1}$ ) and wind (arrows, $\mathrm{m} \mathrm{s}^{-1}$ ) response to climatological latent heating. (a) Low-level response averaged over $\sigma=0.98-0.66$. (b) Midlevel response averaged over $\sigma=0.62-0.3$.

the four experiments are shown in Fig. 9. An intensification of the low-level southwesterly winds over the Arabian Sea and the strengthening of cyclonic anomaly over northern India can be seen in all the experiments, although the magnitude of the low-level response progressively decreases from EXP1 to EXP4. The largest amplitudes of the cyclonic anomaly over northwestern India are seen in EXP1 and EXP2 runs with high CF. For MCSs that are dominated by stratiform rain type, the low-level circulation response is comparatively weaker. The variations in the low-level response among the four experiments are consistent with the vertical distribution of heating (see Mapes 1993). On the other hand, the nature of the midlevel $(\sigma=0.62-0.30)$ anomalous circulation response (Fig. 10) is rather different in the four sensitivity experiments. For large $\mathrm{CF}$, the midlevel wind anomalies are weak and the horizontal scale of the response is localized to the region of forcing. In contrast, the intensity and spatial extent of the midlevel circulation anomalies gradually increases as the percentage of $\mathrm{SF}$ is increased from EXP1 to EXP4. In particular, it is interesting to note the large-scale response in Figs. 10c and $10 \mathrm{~d}$, which extends from near-equatorial Africa around $20^{\circ} \mathrm{E}$ into the South Asian MT region and farther eastward. This issue will be taken up again later in the discussion.

Anomalies of the divergent wind field show a progressive increase of midlevel convergence anomalies around the MCS zone as the stratiform rain fractions are increased from EXP1 to EXP4 (Fig. 11). The stronger midlevel inflows contribute to vorticity generation through the stretching term. We have computed the vorticity stretching term for the low-level and midlevel circulation in the four experiments. The area-averaged values of vorticity stretching term over the MT region are shown for the four experiments in Fig. 12. The gray and black bars in Fig. 12 correspond to vorticity stretching associated with the low-level and midlevel circulations, respectively. It can be readily seen that the vorticity stretching of the low-level circulation is highest in EXP1 when the CF is maximum and gradually decreases as the SF is increased from EXP1 to EXP4. On the other hand, 

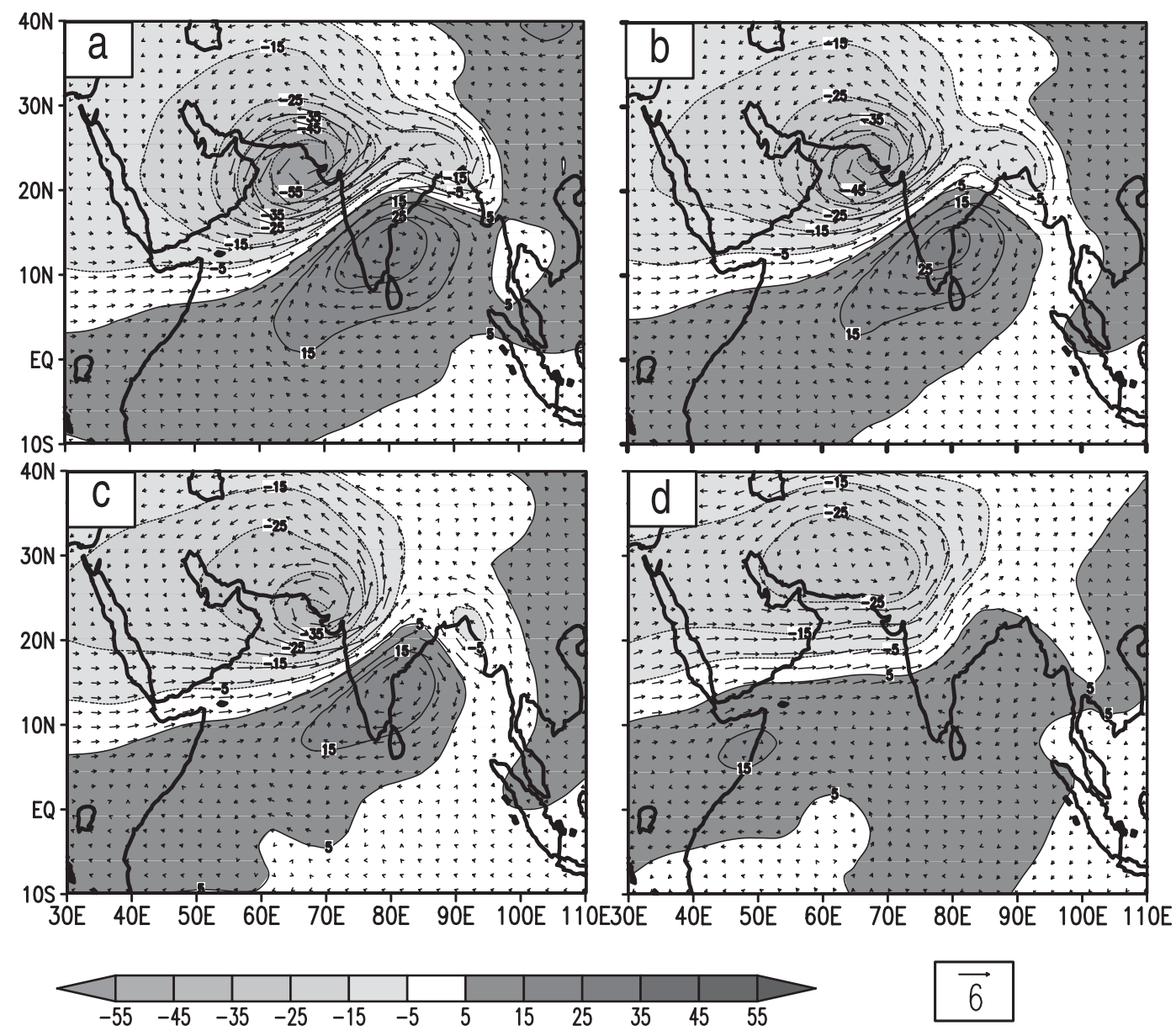

FIG. 9. Model simulated low-level $(\sigma=0.98-0.66)$ anomalous response shown by $\psi$ (shading, $\left.\times 10^{-5} \mathrm{~m}^{2} \mathrm{~s}^{-1}\right)$ and wind (arrows, $\mathrm{m} \mathrm{s}^{-1}$ ) anomalies for the four active monsoon experiments: (a) EXP1, (b) EXP2, (c) EXP3, and (d) EXP4.

the vorticity stretching of midlevel circulation is highest in EXP4 when the SF is a maximum.

\section{Mechanism of upward development of circulation over MT region}

Here, we shall focus on the mechanism of upward development of the layer with cyclonic circulation over the MT region and understand its link with large-scale dynamics. Figure 13 shows vertical profiles of divergence and relative vorticity averaged around the MT region for the four experiments. While the EXP1 and EXP2 simulations show larger convergence (negative divergence) in the lower troposphere as compared to the other two, it is interesting to note that the profile of convergence decreases rapidly in the vertical. It may be noticed that the vertical level of zero convergence in EXP1 is located around $\sigma=0.4$, which is understandable given that the climatological baseline heating component (see
Fig. 6b) is quite large at these vertical levels. Nevertheless, the point relevant to our discussion is the difference in the vertical profiles of divergence among the four experiments. Although the EXP3 and EXP4 simulations show smaller convergence in low levels relative to EXP1 and EXP2, it is interesting to note that the vertical variation in EXP3 and EXP4 reveals a more gradual vertical buildup of convergence well into the middle and upper troposphere, which is conducive for gentle upward motions (Fig. 13a). It may also be noted that the midlevel convergence is quite strong in the EXP3 and EXP4 simulations.

By assuming an approximate balance between latent heating and adiabatic cooling over the tropics, the divergence $D$ can be shown to be proportional to the vertical gradient of heating, so that $D \approx-\partial / \partial \mathrm{z}\left(\rho Q / N^{2}\right)$, where $N$ is the buoyancy frequency and $\rho$ is the air density (see Mapes 1993). Therefore, the gradual vertical buildup of convergence in EXP3 and EXP4 basically 

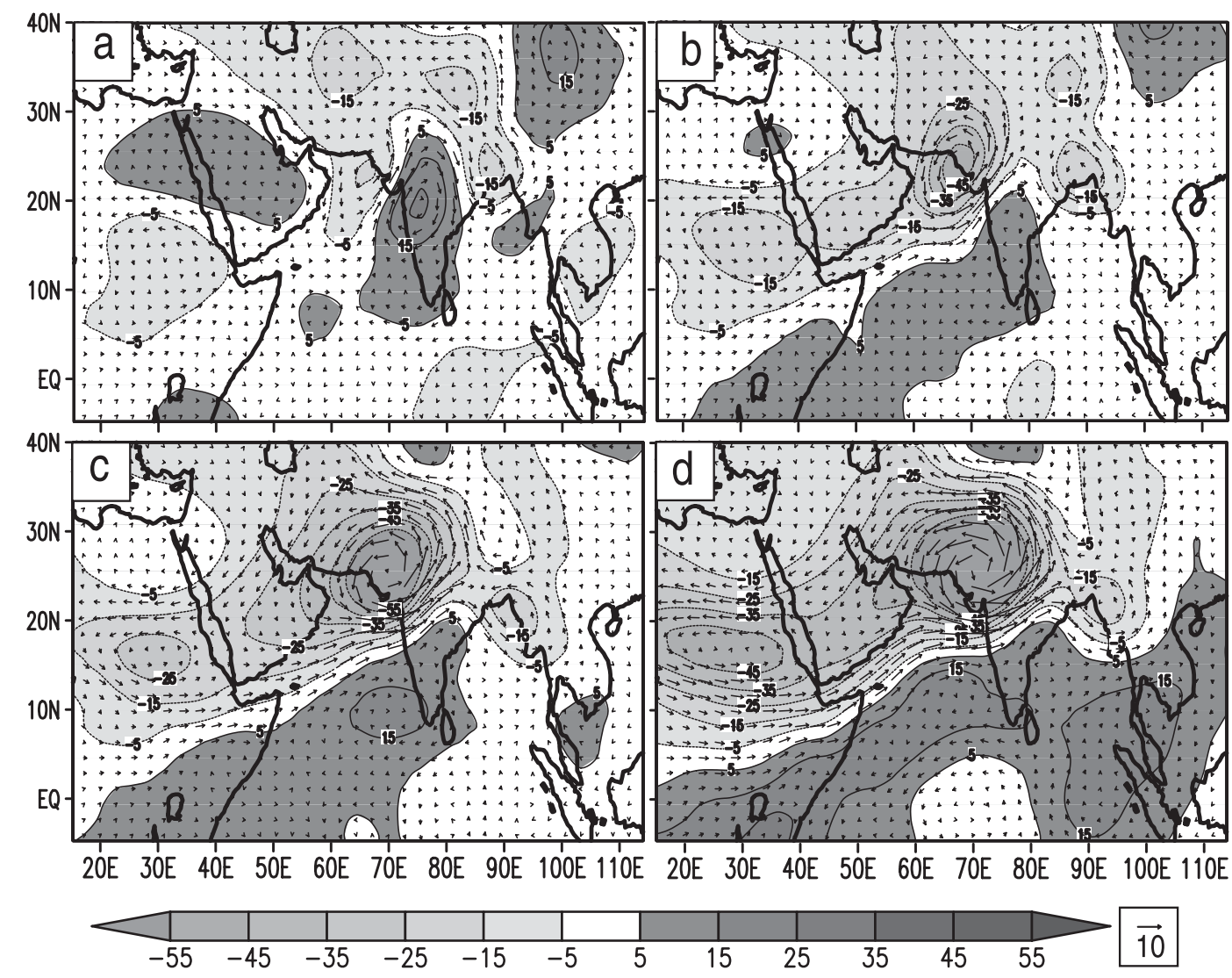

FIG. 10. As in Fig. 9, but for midlevel $(\sigma=0.62-0.3)$ response.

represents the response to positive vertical gradient of heating from the large stratiform population over the MT region. On the other hand, the rapid decrease of convergence in the vertical in EXP1 and EXP2 is consistent with the response to negative vertical gradient of heating associated with convective-type precipitation. The relative vorticity profiles (Fig. 13b) indicate strong cyclonic vorticity in the lower levels for the EXP1 and EXP2 simulations; however, the vorticity rapidly decreases in the vertical above $\sigma=0.6$. In contrast, the EXP3 and EXP4 simulations show a progressive increase of cyclonic vorticity in the vertical well above the midtropospheric level. It is interesting to note that the cyclonic vorticity in EXP3 and EXP4 extends vertically up to nearly $\sigma=0.3$.

The upward development of cyclonic circulation above the midtroposphere in EXP3 and EXP4 represents a dynamically forced uplift, which can also be ascertained from the anomalous temperature response. Since the imposed heating is mostly positive, a negative temperature anomaly is a clean indicator of dynamically forced uplift. Figure 14 shows longitude-pressure sections of temperature anomalies averaged over the $15^{\circ}-27^{\circ} \mathrm{N}$ latitude belt from the four experiments. The temperature anomalies are relative to the CTRL simulation. The anomalous temperature response in the EXP3 and EXP4 simulations, which have a dominant stratiform component of heating, shows a large-scale cooling anomaly in the lower and middle troposphere. On the other hand, negative temperature anomalies are almost negligible in the EXP1 and EXP2 simulations. We have also noted anomalous cooling with magnitudes in the range of $0.6^{\circ}-1.0^{\circ} \mathrm{C}$ in the lower and midtroposphere in the ERA-Interim data during the active monsoon periods (not shown). Past observational studies have documented the cold core structure of monsoon synoptic disturbances (e.g., lows and depressions), which are characterized by colder temperatures, relative to the environment, in the lower levels below 600 hPa (e.g., Keshavamurty 1972; Krishnamurti et al. 1975; Godbole 1977; Keshavamurty et al. 1978; Krishnan et al. 2011). It has been argued that evaporation in the rain area of monsoon synoptic disturbances could be a possible reason for the observed low-level cooling (Keshavamurty 1972). On the other hand, the present results suggest that dynamical uplifts forced by large stratiform heating could also be an important contributor in producing anomalous cooling below the midtroposphere level during active monsoons. 

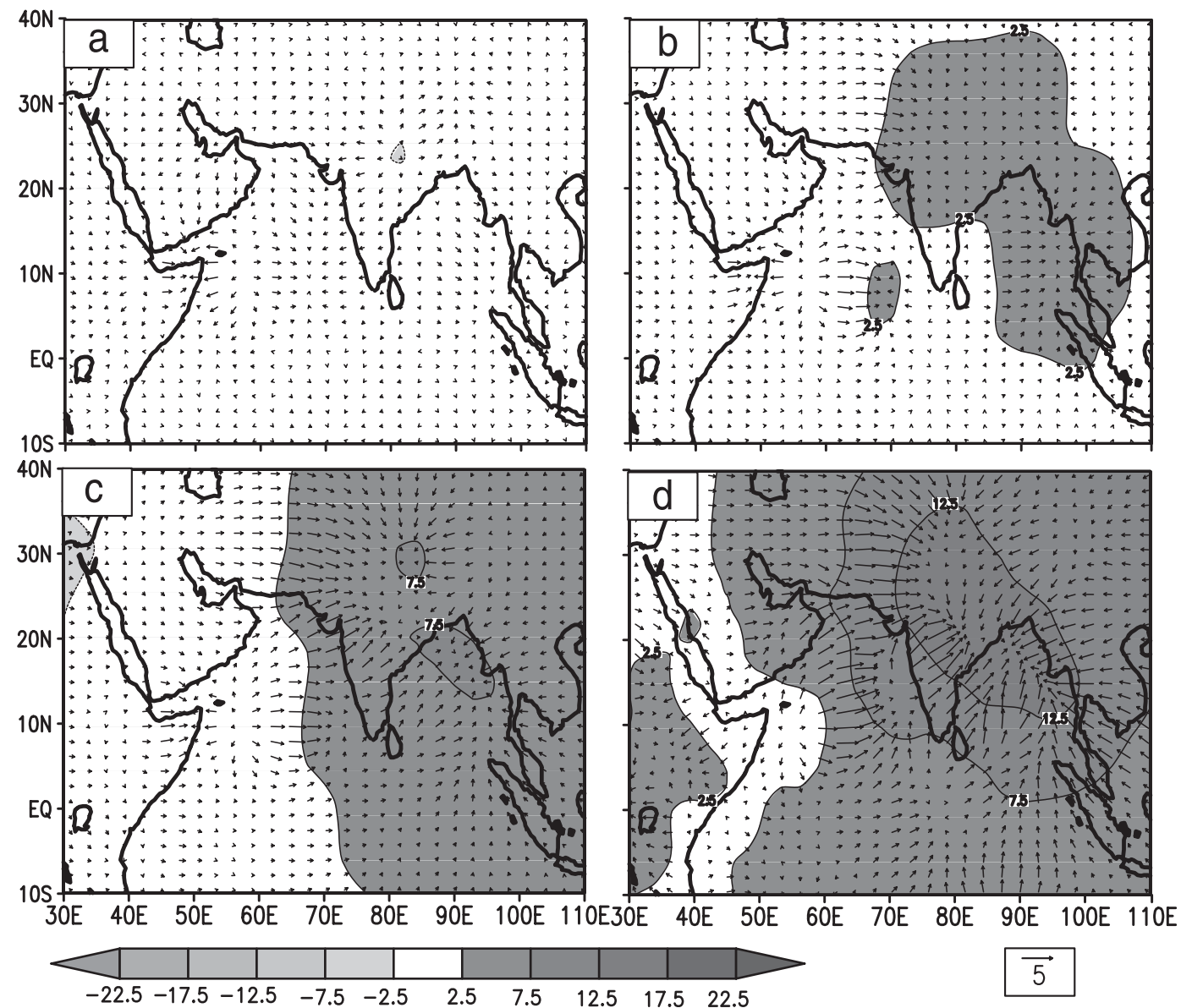

FIG. 11. As in Fig. 10, but for divergent wind and velocity potential $\chi$ (shading, $\times 10^{-5} \mathrm{~m}^{2} \mathrm{~s}^{-1}$ ) anomalies at $\sigma=0.5$.

More rigorous observational and modeling studies will be needed to validate this point and quantify these processes over the MT region.

Considering the fact that the monsoon MCS are located off the equator near $25^{\circ} \mathrm{N}$ and have long life spans, the large-scale midlevel circulation anomalies can be interpreted as a forced Rossby wave response (e.g., Matsuno 1966; Gill 1980; Hoskins and Rodwell 1995). Basically, the vertical gradient of heating (i.e., derivative of heating with potential temperature) over the precipitating regions of the tropics is known to be a source of $\mathrm{PV}$ generation and the circulation response is strongest at the level of the maximum heating gradient (e.g., Mapes 1993; Krishnamurti et al. 2000; Houze 2004). Using the ERA-Interim daily data of PV and wind fields on isentropic levels, we have examined the PV response during active monsoon conditions. Figure 15 shows the active monsoon composite of $\mathrm{PV}$ and wind anomalies on the $330-\mathrm{K}$ isentropic surface, which roughly corresponds to the level of maximum vertical gradient of heating. The composites are constructed by averaging the daily anomalies over all the active monsoon days given in Table 1 . The daily anomalies are relative to the baseline daily climatology obtained from the daily data during 1989-2008. A clear enhancement of PV can be seen over

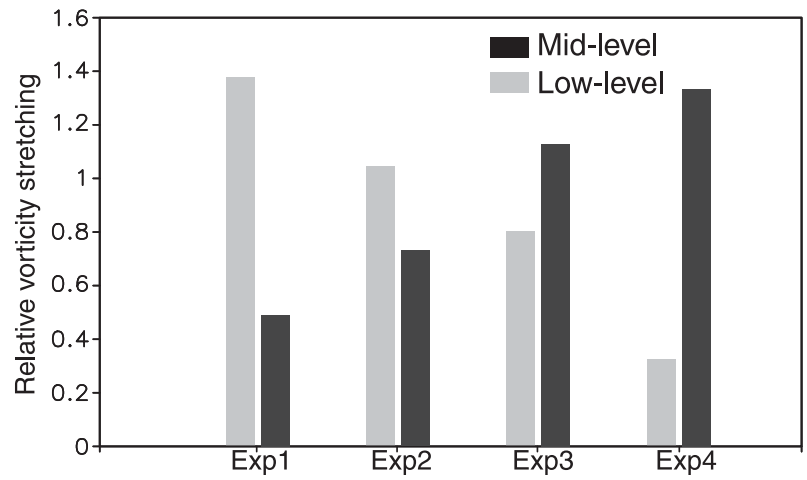

FIG. 12. Histogram showing low-level $(\sigma=0.86$, gray) and midlevel $\left(\sigma=0.5\right.$, black) relative vorticity stretching $\left(\times 10^{-10} \mathrm{~s}^{-2}\right)$ averaged over the $\mathrm{MT}\left(18^{\circ}-28^{\circ} \mathrm{N}, 70^{\circ}-90^{\circ} \mathrm{E}\right)$ for different sets of experiments. 

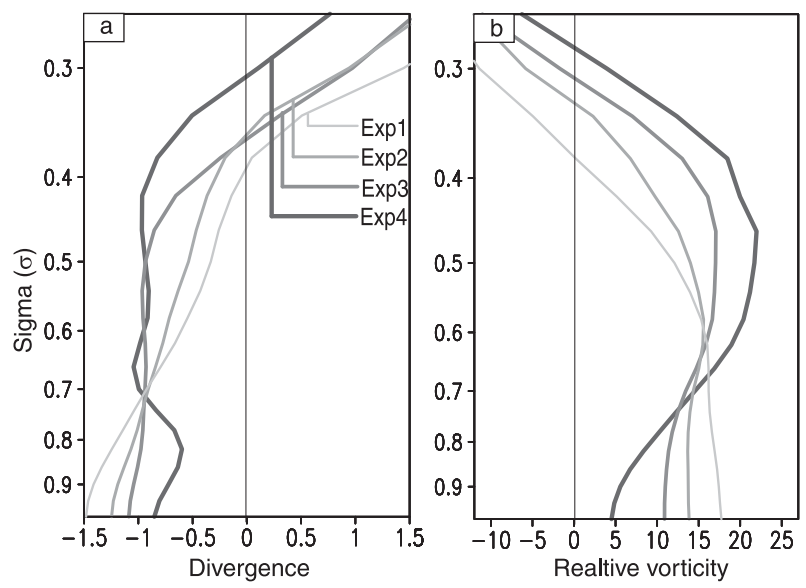

FIG. 13. Vertical profiles of (a) divergence $\left(\times 10^{-6} \mathrm{~s}^{-1}\right)$ and (b) relative vorticity $\left(\times 10^{-6} \mathrm{~s}^{-1}\right)$ averaged over the MT $\left(18^{\circ}-28^{\circ} \mathrm{N}\right.$, $\left.70^{\circ}-90^{\circ} \mathrm{E}\right)$ for the four experiments (EXP1, EXP2, EXP3, and EXP4).

the MT region. More interestingly, the positive PV anomalies located around the $18^{\circ}-25^{\circ} \mathrm{N}$ latitude belt exhibit a large-scale east-west pattern extending from $45^{\circ}$ to $105^{\circ} \mathrm{E}$. The positive $\mathrm{PV}$ anomaly is flanked by westerly anomalies to the south and easterly anomalies to the north, which correspond to a continental-scale cyclonic circulation anomaly over the region. The largescale anomaly pattern in Fig. 15 can be understood as a forced Rossby wave response that disperses the PV westward. The long components of the forced response extend westward up to Africa, while the short components are more locally trapped. The anomalous westerly response to the south of $15^{\circ} \mathrm{N}$ is indicative of equatorward ducting of Rossby waves by the background westerly flow (see Hoskins and Ambrizzi 1993). The equatorward ducting of Rossby waves is more pronounced in the EXP3 and EXP4 simulations, which may partly explain the asymmetry in the circulation response over northwestern India and Southeast Asia in Figs. 10c and 10d.

Based on the above findings, it is suggested that older portions of the organized monsoon MCS, which are predominantly composed of stratiform clouds, exert profound dynamical influence on the MT during active monsoons. Basically, the positive vertical gradient of stratiform heating encourages the vertical buildup of convergence in midlevels and causes vorticity stretching well above the midtroposphere. More importantly, the midlevel convergence and upward development of cyclonic circulation over the MT region are greatly enhanced through the generation of forced large-scale Rossby waves, which extend far westward of the heating almost up to the northern flanks of the African ITCZ. Interestingly, the model simulations showed that an absence of stratiform heating (i.e., $\mathrm{SF}=0$ ) is unfavorable for the upward development of cyclonic circulation above the midtroposphere over the MT region.

\section{Summary and concluding remarks}

While tropical MCSs are an important link between atmospheric convection and large-scale circulation, their influence on various regional and large-scale aspects of the MT dynamics are not fully understood. In the past, the MT has been perceived as a feature largely in the boundary layer and lower atmosphere, although little has been known about its linkage with large-scale dynamics. In this paper, we have addressed a specific question concerning the importance of convective and stratiform components of latent heating on the upward development of cyclonic circulation over the MT region. In particular, we have focused on the role of largescale circulation response in influencing the MT dynamics during active monsoons. This is an important problem since it has implications for improving the simulation of monsoon rainfall through development of better cumulus parameterization schemes. This study has been carried out based on a suite of GCM simulation experiments and supplementary diagnostic analyses of observations.

Observations reveal that active monsoons are characterized by significant enhancement of cyclonic vorticity, which extends vertically up to approximately $350 \mathrm{hPa}$ over the MT region. The strength and spatial extent of the anomalous circulation is found to be larger in the midtroposphere as compared to the lower levels. An interesting finding is that the upward development of cyclonic circulation over the MT during active monsoons is accompanied by large-scale midlevel circulation anomalies that extend over several thousand kilometers westward up to the northern flanks of the African ITCZ. Results from the GCM simulations showed that a progressive increase of stratiform fractions over the monsoon MCS region produced significant increase in the horizontal scale and strength of the midlevel circulation response. In the experiments with high convective rain fractions, the cyclonic response was found to be mostly confined to the lower levels over the MT region and the intensity of the response decreased with height and weakened above the midtroposphere. On the other hand, the simulated circulation response for the high stratiform rain-fraction experiments was characterized by largescale westerly midlevel inflows (convergence) into the MT region, which enhanced the generation of cyclonic vorticity through vorticity stretching well above the midtroposphere.

The present findings suggest that the positive vertical gradient of latent heating from stratiform precipitation produces a gradual vertical buildup of convergence 

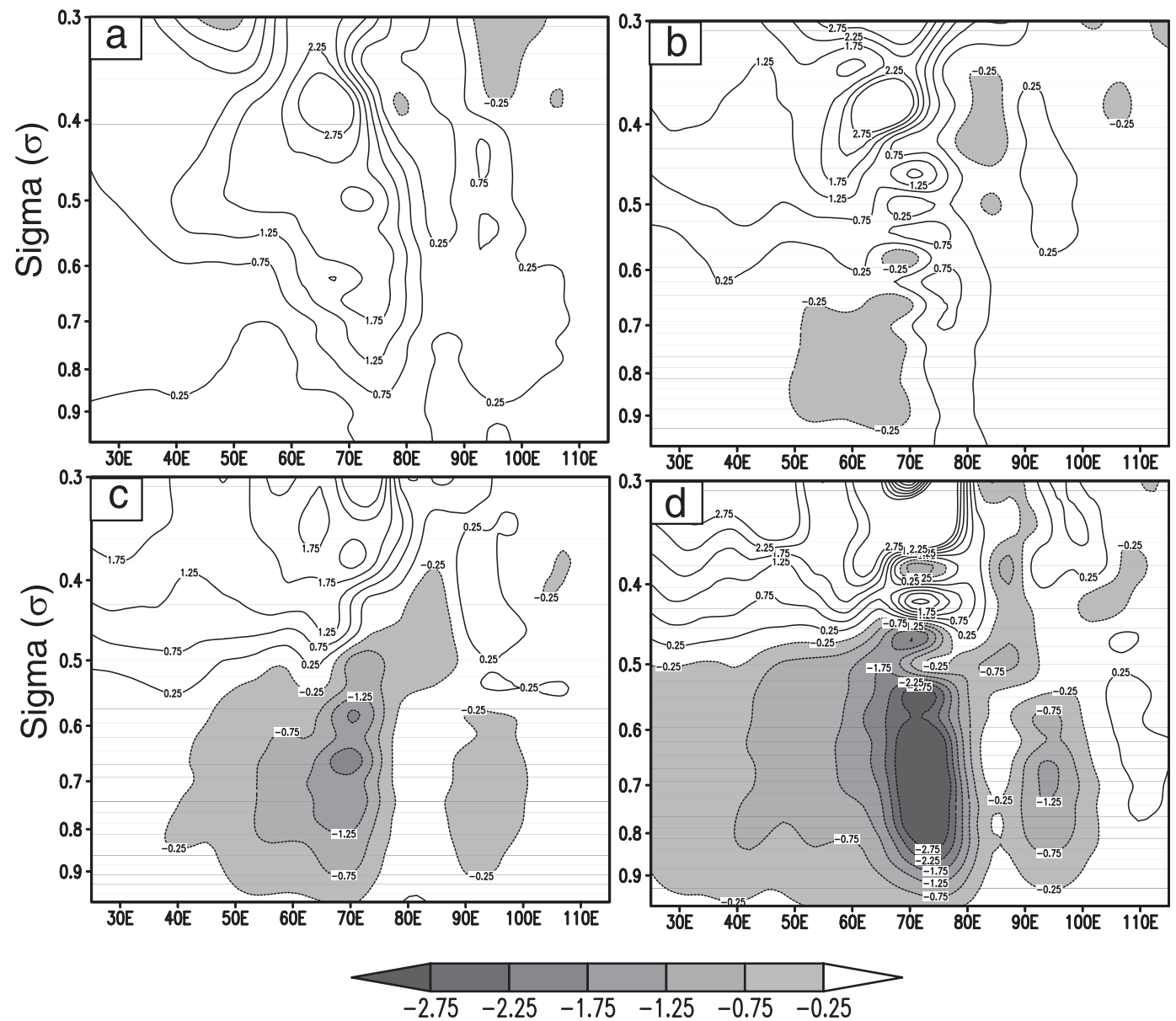

FIG. 14. Longitude-height sections of temperature anomalies averaged over MT $\left(15^{\circ}-27^{\circ} \mathrm{N}\right)$ for the four experiments (EXP1, EXP2, EXP3, and EXP4).

extending above the midtroposphere and encourages vorticity stretching and upward development of cyclonic circulation above the midtroposphere over the MT region. More importantly, it is found that the upward development of cyclonic circulation above the midtroposphere is greatly enhanced through the generation of forced large-scale Rossby waves, which extend far westward almost up to approximately $20^{\circ} \mathrm{E}$ over the northern flanks of the African ITCZ. On the other hand, the response from latent heating due to pure deep convection is mostly localized over the forcing region and is characterized by a rapid decrease of convergence in the vertical. In short, these results highlight the point that as the monsoon MCS evolves, the older portions of the MCS that are primarily composed of stratiform precipitation exert a profound large-scale dynamical influence on the MT.

The use of a dry adiabatic model is a caveat of this work. Previous studies have shown that high specific humidity in midtroposphere can significantly aid the enhancement of stratiform precipitation (e.g., Lin et al.
2004; Tao et al. 1993). Furthermore, midlevel inflows can pump moisture above the midtroposphere and contribute to the MCS activity. Also, large-scale moisture transports from the tropical Indian Ocean by the monsoon

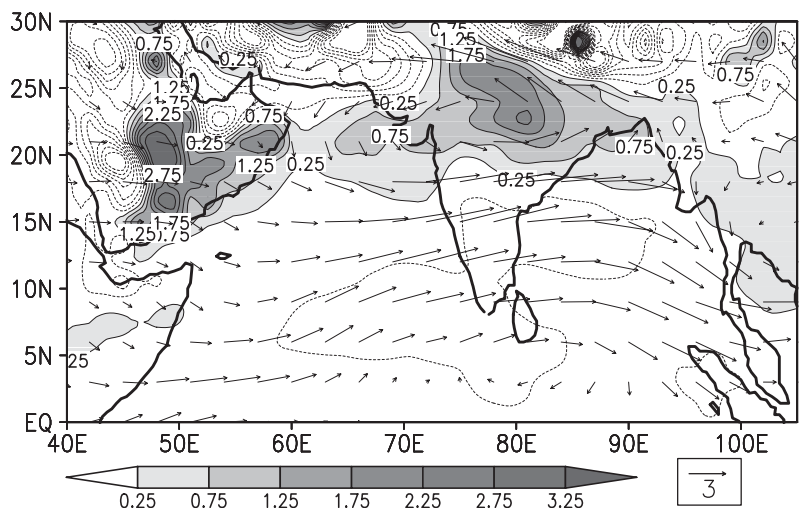

FIG. 15. Anomaly composite of potential vorticity (shading, $\times 10^{-7} \mathrm{~kg} \mathrm{~m}^{2} \mathrm{~s}^{-1} \mathrm{~K}^{-1}$ ) and winds (arrows, $\mathrm{m} \mathrm{s}^{-1}$ ) at the $330-\mathrm{K}$ isentropic surface based on the active monsoon days in Table 1. The data are based on the ERA-Interim. 
cross-equatorial flow can influence the precipitating systems and activity of monsoon synoptic disturbances over the MT region (e.g., Behera et al. 1999; Krishnan et al. 2011; Annamalai 2010). Unraveling the interplay between moist dynamics and MCS over the South Asian monsoon region warrants detailed investigations in the future.

Acknowledgments. The authors thank Prof. B. N. Goswami, Director, IITM, for all the encouragement and support. We specially thank the editor Prof. Robert Houze and the three anonymous reviewers for their valuable suggestions, which have been greatly beneficial in improving the manuscript. We are grateful to Dr. Courtney Schumacher for providing the necessary details needed to construct the latent heating profiles. We also thank Samir Pokhrel for suggestions on TRMM data processing. ADC acknowledges the Council of Scientific and Industrial Research, Govt. of India, for financial support.

\section{REFERENCES}

Alexander, G., R. N. Keshavamurty, U. S. De, R. Chellappa, S. K. Das, and P. V. Pillai, 1978: Fluctuations of monsoon activity. Indian J. Meteor. Geophys., 29, 76-87.

Anjaneyalu, T. S. S., 1969: On the estimates of heat and moisture over the Indian monsoon trough zone. Tellus, 21, 64-75.

Annamalai, H., 2010: Moist dynamical linkage between the equatorial Indian Ocean and the South Asian monsoon trough. J. Atmos. Sci., 67, 589-610.

Awaka, J., T. Iguchi, H. Kumagai, and K. Okamoto, 1997: Rain type classification algorithm for the TRMM precipitation radar. Proc. IGARSS '97, Singapore, IEEE, 1633-1635.

Behera, S. K., R. Krishnan, and T. Yamagata, 1999: Unusual oceanatmosphere conditions in the tropical Indian Ocean during 1994. Geophys. Res. Lett., 26, 3001-3004.

Bourke, W., 1974: A multi-level spectral model. I. Formulation and hemispheric integrations. Mon. Wea. Rev., 102, 687-701.

Cetrone, J., and R. A. Houze Jr., 2009: Anvil clouds of tropical mesoscale convective systems in monsoon regions. Quart. J. Roy. Meteor. Soc., 135, 305-317.

Chattopadhyay, R., B. N. Goswami, A. K. Sahai, and K. Fraedrich, 2009: Role of stratiform rainfall in modifying the northward propagation of monsoon intraseasonal oscillation. J. Geophys. Res., 114, D19114, doi:10.1029/2009JD011869.

Das, P. K., 1986: Monsoons. WMO Rep. 613, 115 pp.

-, and H. S. Bedi, 1981: A numerical model of the monsoon trough. Monsoon Dynamics, J. Lighthill and R. Pearce., Eds., Cambridge University Press, 351-363.

Geisler, J. E., and D. E. Stevens, 1982: On the vertical structure of damped steady circulation in the tropics. Quart. J. Roy. Meteor. Soc., 10, 87-93.

Gill, A. E., 1980: Some simple solutions for heat-induced tropical circulation. Quart. J. Roy. Meteor. Soc., 106, 447-462.

Godbole, R. V., 1977: The composite structure of the monsoon depression. Tellus, 29, 25-40.

Hartmann, D. L., H. H. Hendon, and R. A. Houze Jr., 1984: Some implications of the mesoscale circulations in tropical cloud clusters for large-scale dynamics and climate. J. Atmos. Sci., 41, 113-121.

Hoskins, B. J., and T. Ambrizzi, 1993: Rossby wave propagation on a realistic longitudinally varying flow. J. Atmos. Sci., 50, 1661-1671.

— , and M. J. Rodwell, 1995: A model of the Asian summer monsoon. Part I: The global scale. J. Atmos. Sci., 52, 1329-1340.

Houghton, H. G., 1968: On precipitation mechanisms and their artificial modification. J. Appl. Meteor., 7, 851-859.

Houze, R. A. Jr., 1982: Cloud clusters and large-scale vertical motions in the tropics. J. Meteor. Soc. Japan, 60, 396-410.

- 1997: Stratiform precipitation in regions of convection: A meteorological paradox? Bull. Amer. Meteor. Soc., 78, 2179-2196.

_ 2004: Mesoscale convective systems. Rev. Geophys., 42, RG4003, doi:10.1029/2004RG000150.

— , and D. D. Churchill, 1987: Mesoscale organization and cloud microphysics in a Bay of Bengal depression. J. Atmos. Sci., 44, 1845-1868.

— D. C. Wilton, and B. F. Smull, 2007: Monsoon convection in the Himalayan region as seen by the TRMM Precipitation Radar. Quart. J. Roy. Meteor. Soc., 133, 1389-1411.

Huffman, G. J., R. F. Adler, B. Rudolf, U. Schneider, and P. R. Keehn, 1995: Global precipitation estimates based on a technique for combining satellite-based estimates, rain gauge analysis, and NWP model precipitation information. J. Climate, 8, 1284-1295.

—_, and Coauthors, 1997: The global precipitation climatology project (GPCP) combined precipitation dataset. Bull. Amer. Meteor. Soc., 78, 5-20.

Iguchi, T., T. Kozu, R. Meneghini, J. Awaka, and K. Okamoto, 2000: Rain-profiling algorithm for the TRMM precipitation radar. J. Appl. Meteor., 39, 2038-2052.

,-- , J. Kwiatkowski, R. Meneghini, J. Awaka, and K. Okamoto, 2009: Uncertainties in the rain profiling algorithm for the TRMM Precipitation Radar. J. Meteor. Soc. Japan, 87, 1-30.

Jiang, X., and Coauthors, 2009: Vertical heating structures associated with the MJO as characterized by TRMM estimates, ECMWF reanalyses, and forecasts: A case study during 1998/ 99 winter. J. Climate, 22, 6001-6020.

Kasture, S. V., V. Satyan, and R. N. Keshavamurty, 1991: A model study of the 30-50 day oscillation in the tropical atmosphere. Mausam, 42, 241-248.

Keshavamurty, R. N., 1972: On the vertical tilt of monsoon disturbances. J. Atmos. Sci., 29, 993-995.

— monsoon trough over north India. Mon. Wea. Rev., 98, 315-320.

_ - G. C. Asnani, P. V. Pillai, and S. K. Das, 1978: Some studies on the growth of monsoon disturbances. Proc. Indian Acad. Sci., 87, 61-75.

— S. V. Kasture, and V. Krishnakumar, 1986: 30-50 day oscillation of the monsoon: A new theory. Beitr. Phys. Atmos., 49, 443-454.

Kodama, Y.-M., M. Katsumata, S. Mori, S. Satoh, Y. Hirose, and H. Ueda, 2009: Climatology of warm rain and associated latent heating derived from TRMM-PR observations. J. Climate, 22, 4908-4929.

Koteswaram, P., and N. S. B. Rao, 1963: Formation and structure of Indian summer monsoon depressions. Aust. Meteor. Mag., 41, $62-75$.

Krishnakumar, V., S. V. Kasture, and R. N. Keshavamurty, 1993: Linear and nonlinear studies of the summer monsoon onset vortex. J. Meteor. Soc. Japan, 71, 1-20. 
Krishnamurti, T. N., and H. N. Bhalme, 1976: Oscillations of a monsoon system. Part I: Observational aspects. J. Atmos. Sci., 33, 1937-1954.

— gating mode and "breaks in the monsoon." Tellus, 32, 15-26.

—, and N. Surgi, 1987: Observational aspects of the summer monsoon. Monsoon Meteorology, C.-P. Chang and T.N. Krishnamurti, Eds., Oxford University Press, 3-25.

—, M. Kanamitsu, R. V. Godbole, C.-B. Chang, F. Carr, and J. H. Chow, 1975: Study of a monsoon depression. I. Synoptic structure. J. Meteor. Soc. Japan, 53, 227-239.

—, B. Jha, H. S. Bedi, and U. C. Mohanty, 2000: Diabatic effects on potential vorticity over the global tropics. J. Meteor. Soc. Japan, 78, 527-542.

—, A. Chakraborty, and A. K. Mishra, 2010: Improving multimodel forecasts of the vertical distribution of heating using the TRMM profiles. J. Climate, 23, 1079-1094.

Krishnan, R., and S. V. Kasture, 1995: Sensitivity of the tropical nonlinear stationary Kelvin and Rossby waves to the vertical structure of heating. Proc. Indian Acad. Sci., 104, 579-606, doi:10.1007/BF02839298.

— oscillations of northern summer monsoon by El Niño and Southern Oscillation (ENSO). Meteor. Atmos. Phys., 60, 237-257.

—, C. Zhang, and M. Sugi, 2000: Dynamics of breaks in the Indian summer monsoon. J. Atmos. Sci., 57, 1354-1372.

—-, M. Mujumdar, V. Vaidya, K. V. Ramesh, and V. Satyan, 2003: The abnormal Indian summer monsoon of 2000. J. Climate, 16, 1177-1194.

— , K. V. Ramesh, B. K. Samala, G. Meyers, J. M. Slingo, and M. J. Fennessy, 2006: Indian Ocean-monsoon coupled interactions and impending monsoon droughts. Geophys. Res. Lett., 33, L08711, doi:10.1029/2006GL025811.

— , V. Kumar, M. Sugi, and J. Yoshimura, 2009: Internal feedbacks from monsoon-midlatitude interactions during droughts in the Indian summer monsoon. J. Atmos. Sci., 66, 553-578.

— D. C. Ayantika, V. Kumar, and S. Pokhrel, 2011:The longlived monsoon depressions of 2006 and their linkage with the Indian Ocean Dipole. Int. J. Climatol., in press, doi:10.1002/ joc.2156.

Lin, J., B. Mapes, M. Zhang, and M. Newman, 2004: Stratiform precipitation, vertical heating profiles, and the Madden-Julian oscillation. J. Atmos. Sci., 61, 296-309.

Mapes, B. E., 1993: Gregarious tropical convection. J. Atmos. Sci., 50, 2026-2037.

— western Pacific mesoscale convective systems. J. Atmos. Sci., 52, 1807-1828.

Matsuno, T., 1966: Quasi-geostrophic motions in the equatorial area. J. Meteor. Soc. Japan, 44, 25-42.

Meneghini, R., J. A. Jones, T. Iguchi, K. Okamoto, and J. Kwiatkowski, 2001: Statistical methods of estimating average rainfall over large space-timescales using data from the TRMM Precipitation Radar. J. Appl. Meteor., 40, 568-585.

Miller, F. R., and R. N. Keshavamurthy, 1968: Structure of Arabian Sea Monsoon System. IIOE Meteor. Monogr., Vol. 1, East-West Center Press, 94 pp.
Narasimha, R., D. R. Sikka, and A. Prabhu, 1997: The Monsoon Trough Boundary Layer. Indian Academy of Sciences, 422 pp.

Press, W. H., B. P. Flannery, S. A. Teukolsky, and W. T. Vetterling, 1992: Numerical Recipes: The Art of Scientific Computing. 2nd ed. Cambridge University Press, 963 pp.

Rajeevan, M., S. Gadgil, and J. Bhate, 2010: Active and break spells of the Indian summer monsoon. J. Earth Syst. Sci., 119, 229-247.

Ramamurthy, K., 1969: Monsoon of India: Some aspects of the 'break' in the Indian southwest monsoon during July and August. Forecasting Manual IV-18.3, India Meteorological Dept., 1-57.

Rao, Y. P., 1976: Southwest monsoon. Synoptic Meteorology, IMD Meteor. Monogr., No. 1, 367 pp.

Rodwell, M. J., and B. H. Hoskins, 1996: Monsoons and the dynamics of deserts. Quart. J. Roy. Meteor. Soc., 122, 1385-1404.

Romatschke, U., and R. A. Houze Jr., 2011: Characteristics of precipitating convective systems in the South Asian monsoon. J. Hydrometeor., 12, 3-26.

Schumacher, C., R. A. Houze Jr., and I. Kraucunas, 2004: The tropical dynamical response to latent heating estimates derived from the TRMM Precipitation Radar. J. Atmos. Sci., 61, $1341-1358$.

Sikka, D. R., and S. Gadgil, 1980: On the maximum cloud zone and the ITCZ over Indian longitudes during the southwest monsoon. Mon. Wea. Rev., 108, 1840-1853.

_ , and R. Narasimha, 1995: Genesis of the Monsoon Trough Boundary Layer Experiment (MONTBLEX). Proc. Indian Acad. Sci., 104, 157-187.

Simmons, A., S. Uppala, D. Dee, and S. Kobayashi, 2006: ERAInterim: New ECMWF reanalysis products from 1989 onwards. ECMWF Newsletter, No. 110, ECMWF, Reading, United Kingdom, 25-35. [Available online at http://www.ecmwf.int/ publications/newsletters/pdf/110_rev.pdf.]

Stano, G., T. N. Krishnamurti, T. S. V. Vijaya Kumar, and A. Chakraborty, 2002: Hydrometeor structure of a composite monsoon depression using the TRMM radar. Tellus, 54A, 370-381.

Sundaram, S., R. Krishnan, A. Dey, and P. Swapna, 2010:Dynamics of intensification of the boreal summer monsoon flow during IOD events. Meteor. Atmos. Phys., 107, 17-31, doi:10.1007/ S00703-010-0066-z.

Tao, W.-K., J. Simpson, C. H. Sui, B. Ferrier, S. Lang, J. Scala, M. D. Chou, and K. Pickering, 1993: Heating, moisture, and water budgets of tropical and midlatitude squall lines: Comparisons and sensitivity to longwave radiation. J. Atmos. Sci., 50, 673-690.

_ - and Coauthors, 2001: Retrieved vertical profiles of latent heat release using TRMM rainfall products for February 1998. J. Appl. Meteor., 40, 957-982.

Wang, B., 2004: The Asian Monsoon. Springer/Praxis, 787 pp.

Yasunari, T., 1979: Cloudiness fluctuation associated with the Northern Hemisphere summer monsoon. J. Meteor. Soc. Japan, 57, 227-242.

Zhang, Z., and T. N. Krishnamurti, 1996: A generalization of Gill's heat-induced tropical circulation. J. Atmos. Sci., 53, 10451056. 